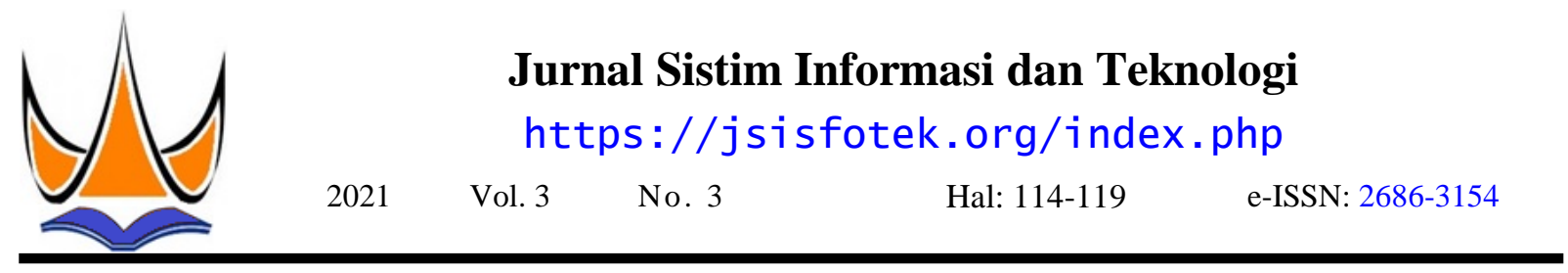

\title{
Identifikasi dalam Penetapan Staf Dosen dan Karyawan Berprestasi dengan Menggunakan Metode SMART
}

\author{
Nur Azizah $^{1 \bowtie}$, Gunadi Widi Nurcahyo ${ }^{2}$ \\ ${ }^{1,2,}$ Universitas Putra Indonesia YPTK Padang \\ azizahd03@gmai1.com
}

\begin{abstract}
STMIK Indonesia Padang annually selects the best lecturers and employees to give appreciation for the performance of lecturers and employees. Lecturers and employees who take the assessment to appreciate the Performance Appraisal must meet the requirements and participate in the assessment process. The purpose of this research is to identify in determining the staff of lecturers and staff with achievement who are shorter in terms of calculations and also in accordance with the criteria. The sample in this study consisted of 4 lecturer data and 3 employee data taken randomly from 36 lecturer data and 26 employee data sourced from LP3M STMIK Indonesia Padang. Based on the analysis of lecturer and employee data, several criteria were obtained for processing these criteria, namely for lecturers the suitability of teaching materials with RPS (K) (Q1) teaching materials $(\mathrm{Q} 2)$, teaching time $(\mathrm{Q} 3)$, research $(\mathrm{Q} 4)$ and GPA (Q5). ) then for employees, namely attendance (R1), performance (R2) and loyalty (R3). The method in this research is SMART (Simple Multi - Attribute Rating Technique) because this method is able to solve problems with multi-criteria. The results of the data testing obtained were Lecturers with achievements, namely DHD lecturers with a value of 0.8521 and outstanding employees, namely ARD employees with a value of 0.9998 . The results of this study are expected to provide solutions for the identification of outstanding lecturers and staff at STMIK Indonesia Padang based on predetermined criteria.
\end{abstract}

Keywords: SMART, Performance, Employees, Lecturer, SPK.

Abstrak

STMIK Indonesia Padang setiap tahunnya melakukan pemilihan dosen dan karyawan terbaik guna memberikan apresiasi terhadap kinerja dari dosen dan karyawan. Dosen dan karyawan yang mengikuti penilaian untuk apresiasi Penilaian Kinerja harus memenuhi syarat dan ikut dalam proses penilaian. Tujuan dari penelitian ini adalah untuk mengidentifikasi dalam penetapan staf dosen dan karyawan berprestasi yang lebih singkat dalam hal perhitungannya dan juga sesuai dengan kriteria.Sampel dalam penelitian ini sebanyak 4 data dosen dan 3 data karyawan diambil secara acak dari 36 data dosen dan 26 data karyawan yang bersumber dari LP3M STMIK Indonesia Padang. Berdasarkan analisis terhadap data dosen dan karyawan tersebut didapatkan beberapa kriteria untuk melakukan pengolahan kriteria tersebut yaitu untuk dosenkesesuaian bahan ajar dengan RPS (K) (Q1) bahan ajar (Q2), waktu mengajar (Q3), penelitian (Q4) dan IPK (Q5) selanjutnya untuk karyawan yaitu kehadiran (R1), kinerja (R2) dan loyalitas (R3). Metode dalam penelitian ini yaitu SMART (Simple Multi Attribute Rating Technique) karena metode ini mampu menyelesaikan masalah dengan multicriterias. Hasil pengujian data didapatkan Staf Dosen berprestasi yaitu Dosen DHD dengan nilai 0.8521 dan karyawan berprestasi yaitu karyawan ARD dengan nilai 0.9998. Hasil dari penelitian ini diharapkan mampu memberikan solusi untuk identifikasi staf dosen dan karyawan berprestasi pada STMIK Indonesia Padang berdasarkan kriteria yang telah ditetapkan.

Kata kunci: SMART, Kinerja, Karyawan, Dosen, SPK.

(c) 2021 JSisfotek

\section{Pendahuluan}

Berdasarkan pada SK Buku Panduan Pemilihan Dosen dan Karyawan berprestasi, Sekolah Tinggi Manajemen Informatika dan Komputer (STMIK) Indonesia Padang setiap tahunnya melakukan pemilihan dosen dan karyawan berprestasi guna memberikan apresiasi terhadap kinerja dari dosen dan karyawan. Dosen dan karyawan yang mengikuti penilaian untuk apresiasi Penilaian Kinerja harus memenuhi syarat dan ikut dalam proses penilaian. Karyawanpada sebuah instansi memiliki tugas dan kewajiban yang harus dijalankan sesuai dengan aturan instansi [1]. Kinerja merupakan suatu pencapaian dari setiap orang berdasarkan kesepakatan bersama dengan organisasi atau perusahaan penyelenggara sesuai dengan target atau tujuan yang harus tercapai dalam masa waktu tertentu yang telah disepakati sebelumnya [2]. Saat ini proses pemilihan dosen dan karyawan terbaik di STMIK Indonesia Padang masih diolah di Microsoft Excel dan data pendukungnya terkadang lambat dari masingmasing unit. Sehingga menyebabkan lamanya pemrosesan dalam pemilihan.

Selain itu metode ini juga dapat mengatasi keterlambatan data pendukung unit dalam menentukan dosen dan karyawan terbaik di STMIK Indonesia Padang.

Sistem Pendukung Keputusan atau Decision Support System (DSS) suatu sistem berbasis komputer yang dapat membantu dalam proses pengambilan keputusan, serta sistem informasi komputer yang fleksibel, interaktif, dan adaptif yang secara khusus dikembangkan untuk membantu penyelesaian masalah manajemen yang tidak tertataguna meningkatkan 
kualitas dalam mengambil keputusan [3]. Sistem efektif. Serta perhitungan yang cepat untuk dapat Pendukung Keputusan adalah sistem informasi yang mengatasi keterlambatan data.

menunjang mengetahui peluang keputusan atau memberikan informasi untuk membantu dalam proses pengambilan keputusan [4].
Berdasarkan latar belakang diatas, dapat dirumuskan permasalahan yang akan diteliti yaitu: bagaimana metode SMART dapat membantu dalam Keputusan yang diambil dalam penyelesaiansebuah mengidentifikasi staf dosen dan karyawan berprestasi. masalah berdasarkan struktur masalahnya terbagi Adapun kriteria yang digunakan yaitu untuk dosen menjadi 3 (tiga) yaitu:

a. Keputusan Terstruktur (Structured Decision) Keputusan yang dilakukan secara berulang-ulang danbersifat rutin. Prosedur pengambilan keputusannya juga jelas.

b. Keputusan Semi Terstruktur (Semi Structured Decision) kesesuaian bahan ajar dengan RPS (K) (Q1), bahan ajar(Q2), waktu mengajar (Q3), penelitian (Q4)dan IPK (Q5), selanjutnya untuk karyawan yaitu kehadiran (R1), kinerja (R2) dan loyalitas (R3).

\section{Metodologi Penelitian} Keputusan ini mempunyai 2 sifat. Sebagian tetap kerja di mana kerangka kerja ini perlu rancang agar dilakukan dengan pengambilan keputusan dan penelitian bisa dilakukan dengan terstruktur dan terarah sebagian laginya bisa ditangani oleh komputer. sesuai tujuan yang diharapkan. Kerangka kerja

c. Keputusan Tak Terstruktur (Unstructured merupakan tahapan-tahapan proses penelitan yang Decision) Penanganan keputusan ini rumit karena tidak berkaitan seperti pada Gambar 1 . berulang-ulang dan tidak selalu terjadi [5].

SMART adalah metode pengambilan keputusan multiatribut di mana setiap alternatif terdiri dari beberapa kriteria yang memiliki nilai dan pada masing masing kriteria mempunyai bobot untuk menunjukkan betapa berartinya suatu nilai dibandingkan dengan kriteria yang lainnya [6]. Nilai ini di rata - rata dengan skala tertentu [7].

SMART menggunakan model aditif linier untuk memprediksi nilai setiap alternatif. Untuk beberapa pengambilan keputusan atau klasifikasi atribut, hubungan yang mendasari antara atribut dan variabel tujuan seringkali sangat tidak pasti dan tidak tepat [8].

Penelitian dengan metode SMART sudah banyak dilakukan oleh peneliti dengan berbagai macam masalah, di antaranya penelitian untuk penerima beasiswa Yayasan AMIK Tunas Bangsa [9]. Penelitian untuk menentukan Team Leader, Supervisor dan Facility Services pada sebuah Perusahaan Jasa [10]. Penentuan kelayakan kredit dengan menggunakan Weighted Product dan metode SMART di Koperasi SPB [11]. Penelitian tentang penentuan prestasi siswa dengan metode SMART [12]. Penelitian tentang membandingkan dua kriteria utama pembelajaran dengan metode SMART untuk mengetahui pemeringkatan siswa [13]. Metode ini juga berhasil menghitung faktor pembobotan Analisis potensi keberlanjutan dan CDM dari proyek bioenergi baru vs konvensional di Asia Selatan [14]. Metode SMART digunakan dalam mengevaluasi hasil uji coba lahan dengan membandingkan empat strategi pengelolaan hama yang berbeda [15].

Dalam penelitian ini dilakukan identifikasi penetapan dan dosen karyawan berprestasi menggunakan metode SMART. Penelitian ini dilakukan berdasarkan bobot dan kriteria-kriteria yang telah ditentukan.Agar nantinya bisa dicapai sebuah analisa yang efisien dan

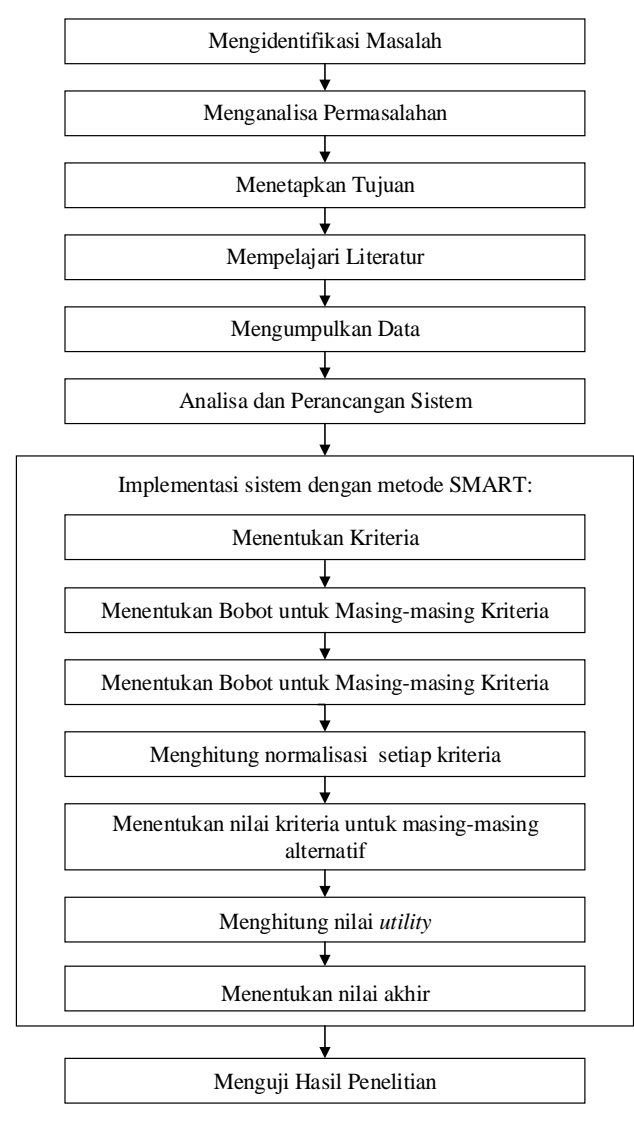

Gambar 1. Kerangka Kerja Penelitian

\section{a. Mengidentifikasi Masalah}

Mengidentifikasi masalah merupakan tahap di mana objek penelitian merumuskan masalahnya. Penetapan rumusan masalah bertujuan agar penelitian menjadi terarah dan tidak mengambang dari batasan-batasan masalah yang akan diteliti. Adapun batasan masalah pada penelitian ini yaitu membangun sebuah Sistem Pendukung Keputusan dengan menerapkan metode SMART untuk identifikasi penetapan staf dosen dan 
karyawan berprestasisesuai dengan bobot dan kriteria yang telah ditentukan dan SPK ini dirancang hanya sebagai alat bantu bagi LPPM STMIK Indoneisa Padang dalamproses identifikasi penetapan staf Dosen dan Karyawan berprestasi.

\section{b. Menganalisa Permasalahan}

Menganalisa permasalahan merupakan langkah memahami batasan dan ruang lingkup permasalahan yang telah ditetapkan, agar hasil dari penelitian sesuai dengan yang diharapkan.

\section{c. Menetapkan Tujuan}

Tujuan penelitian ditetapkan agar penelitiam terfokus dan memiliki arah yang jelas, sehingga hasil penelitian ini selanjutnya dapat digunakan oleh pihak yang membutuhkan.

\section{d. Mempelajari Literatur}

Mempelajari literatur merupakan tahapan untuk Analisa sistem merupakan suatu kegiatan yang memahami teori-teori yang berhubungan dengan dilakukan bertujuan untuk mengetahui permasalahanpenelitian ini. Tujuannya adalah agar peneliti dapat permasalahan serta kendala-kendala yang terjadi pada menentukan target yang akan dicapai. Sumber literatur sistem untuk dapat dilakukan perbaikan.

didapat dari jurnal nasional maupun internasional serta buku dan internet yang membahas tentang metode SMART.

e. Mengumpulkan Data v. Menghitung nilai utility untuk masing-masing kriteria.

vi. Menentukan nilai akhir.

vii. Melakukan perangkingan.

\section{h. Menguji Hasil Penelitian}

Tahapan ini dilakukan dengan tujuan untuk memperbaiki kinerja dari sistem yang tidak sesuai dengan kebutuhan fungsional yang telah direncanakan sebelumnya. Tahap pengujian dilakukan untuk membuktikan bahwa setiap proses yang telah diterapkan ke dalam aplikasi sistem pendukung keputusan ini dapat berjalan dengan baik dan dapat memberikan hasil yang harapkan.

\section{Hasil dan Pembahasan}

\subsection{Analisa Sistem}

Pada tahapan analisa sistem kebutuhan-kebutuhan pengguna ditentukan untuk mempermudah dalam membuat perancangan, yang dilakukan sebelum membuat perancangan sistem baru. Analisa sistem dilakukan agar permasalahan yang ada dapat diketahui, Tahap berikutnya dalam menyelesaikan masalah yaitu sehingga analisa permasalahan yang ditemukan dapat mengumpulkan data. Maka dalam pengumpulan data dirumuskan pemecahan permasalahannya.

itu mesti dilakukan secara baik dan benar. Adapun cara

yang dilakukan antara lain membaca buku, literatur 3.2. Perhitungan Metode SMART

serta jurnal yang berkaitan dengan penelitian. Metode

yang digunakan untuk pengumpulan data dipenelitian Perhitungan metode SMART merupakan tahap-tahap yaitu melalui wawancara dengan pihak LPPM STMIK yang dilakukan untuk mencari alternatif terbaik melalui Indonesia Padang mengenai penetapan dosen dan beberapa faktor yang beragam,tahap-tahappada metode karyawan berprestasi di STMIK Indonesia Padang. $\quad$ SMART yaitu:

\section{f. Analisa dan Perancangan Sistem}

\subsubsection{Kriteria}

Pada tahap ini dilakukan analisa dan perancangan Tahapan awal pada penerapan perhitungan metode sistem yang meliputi penentuan lokasi penelitian di SMART ini yaitu menetukan kriteria untuk identifikasi STMIK Indonesia Padang.Selanjutnya pengumpulan pemilihan staf dosen dan karyawan berprestasi. data yang di dapat dari pihak LP3M. Data yang didapat Kriteria-kriteria yang dipakai dalam identifikasi yaitu data dosen, data karyawan, proses penilaian dosen pemilihan staf dosen dan karyawan berprestasidapat berprestasi 2019-2021 dan bonus tahunan karyawan dilihat pada Tabel 1 dan Tabel 2 Berikut ini berikut ini: 2018. Setelah mendapatkan data, selanjutnya proses perancangan metode SMART.

\footnotetext{
Proses Perancangan SMART

i. Menentukanpertama kali kriteria-kriteria yang akandigunakan sebagai tolak ukur dalam menyelesaikan masalah.

ii. Menentukan bobot untuk setiap kriteria.

iii. Menghitung normalisasi dari setiap kriteria.

iv. Menentukan nilai pada masing-masing kriteria untuk masing-masing alternatif.
}

Tabel 1. Kriteria Dosen

\begin{tabular}{cl}
\hline No & \multicolumn{1}{c}{ Kriteria } \\
\hline 1. & Kesesuaian Bahan Ajar dengan RPS (K) \\
2. & Bahan Ajar \\
3. & Waktu Mengajar \\
4. & Penelitian \\
5. & IPK \\
\hline
\end{tabular}

Tabel 2. Kriteria Karyawan

\begin{tabular}{cl}
\hline No & \multicolumn{1}{c}{ Kriteria } \\
\hline 1. & Kehadiran \\
2. & Kinerja
\end{tabular}

Jurnal Sistim Informasi dan Teknologi Vol. 3 No. 3 (2021) 114-119 


3. Loyalitas

\subsubsection{Bobot}

Tahapan selanjutnya yaitu menentukan bobot untuk algoritma masing-masing kriteria yang ada kemudian normalisasi bobot. Berikut adalah tabel nilai bobot kriteria untuk 3.2.4. Nilai Utility dosen dan karyawan.

Tabel 3. Nilai Bobot Kriteria Dosen

\begin{tabular}{clc}
\hline No & \multicolumn{1}{c}{ Kriteria } & Bobot \\
\hline 1. & $\begin{array}{l}\text { Kesesuaian Bahan } \\
\text { dengan RPS (K) }\end{array}$ & 100 \\
2. & Bahan Ajar & 95 \\
3. & Waktu Mengajar & 90 \\
4. & Penelitian & 90 \\
5. & IPK & 85 \\
\hline \multicolumn{2}{c}{ Total } \\
\hline
\end{tabular}

Tabel 4. Nilai Bobot Kriteria Karyawan

\begin{tabular}{clr}
\hline No & \multicolumn{1}{c}{ Kriteria } & Bobot \\
\hline 1. & Kehadiran & 100 \\
2. & Kinerja & 95 \\
3. & Loyalitas & 85 \\
\hline & Total & 280 \\
\hline
\end{tabular}

Setelah menentukan bobot, lalu lakukan normalisasi. Normalisasi Bobot dilakukan dengan menggunakan Rumus (1).

$$
\text { Normalisasi } A_{x}=\frac{A_{x}}{\sum_{y=1}^{z} A z}
$$

Dimana Normalisasi $A_{x}$ merupakan normalisasi bobot kriteria ke $\mathrm{x}, \mathrm{A}_{\mathrm{x}}$ merupakan nilai bobot kriteria ke $\mathrm{x}, \mathrm{y}$ merupakan jumlah kriteria dan Az merupakan bobot a. kriteria ke $\mathrm{z}$.

Tabel 5 dan 6 berikut adalah hasil normalisasi bobot kriteria dosen dan karyawan.

Tabel 5. Normalisai Bobot Kriteria Dosen

\begin{tabular}{clcc}
\hline No & \multicolumn{1}{c}{ Kriteria } & Bobot & Normalisasi \\
\hline 1. & Kesesuaian Bahan Ajar dengan & 100 & 0.2173 \\
& RPS (K) & & \\
2. & Bahan Ajar & 95 & 0.2065 \\
3. & Waktu Mengajar & 90 & 0.1956 \\
4. & Penelitian & 90 & 0.1956 \\
5. & IPK & 85 & 0.1847 \\
\hline & Total & 460 & \\
\hline
\end{tabular}

Tabel 6. Nilai Bobot Kriteria Karyawan

\begin{tabular}{clrc}
\hline No & Kriteria & Bobot & Normalisasi \\
\hline 1. & Kehadiran & 100 & 0.3571 \\
2. & Kinerja & 95 & 0.3392 \\
3. & Loyalitas & 85 & 0.3035 \\
\hline & Total & 280 & \\
\hline
\end{tabular}

3.2.3. Menentukan Nilai Kriteria untuk Masing Masing Altenatif
Nilai kriteria untuk masing-masing alternatif dapat berupa kuantitatif (angka) atau kualitatif. Nilai kriteria untuk kualitatif (kurang baik, baik, sangat baik). Nilai kriteria ini adalah data penilaian bagi masing-masing staf dosen dan pegawai yang akan digunakan dalam

Normalisasi bobot kriteria yang dilakukan pada Tabel 5 dan 6 digunakan untuk menentukan nilai utility. Sebelum menentukan nilai utility, terlebih dahulu kita menentukan nilai maksimal dan nilai minimal dari masing-masing kriteria setiap alternatif.

Tabel 7. Nilai Bobot Kriteria Dosen

\begin{tabular}{clrrrrr}
\hline No & $\begin{array}{c}\text { Alternatif } \\
\text { Dosen }\end{array}$ & Q1 & Q2 & Q3 & Q4 & Q5 \\
\hline 1 & AIM (D1) & 100 & 100 & 81 & 20 & 76 \\
2 & AMU (D2) & 100 & 100 & 76 & 0 & 79 \\
3 & WHY (D3) & 0 & 50 & 98 & 100 & 88 \\
4 & DHD (D4) & 100 & 100 & 100 & 30 & 88 \\
5 & LMP (D5) & 0 & 0 & 93 & 0 & 79 \\
6 & STA (D6) & 100 & 100 & 99 & 20 & 89 \\
\hline & Max & $\mathbf{1 0 0}$ & $\mathbf{1 0 0}$ & $\mathbf{1 0 0}$ & $\mathbf{1 0 0}$ & $\mathbf{8 9}$ \\
\hline & Min & $\mathbf{0}$ & $\mathbf{0}$ & $\mathbf{7 6}$ & $\mathbf{0}$ & $\mathbf{7 6}$ \\
\hline
\end{tabular}

Tabel 8. Nilai Bobot Kriteria Karyawan

\begin{tabular}{clrrr}
\hline No & $\begin{array}{c}\text { Alternatif } \\
\text { Karyawan }\end{array}$ & Q1 & Q2 & Q3 \\
\hline 1 & ARD (K1) & 100 & 100 & 100 \\
2 & HTA (K2) & 84 & 67 & 0 \\
3 & JPA (K3) & 100 & 33 & 0 \\
\hline & Max & $\mathbf{1 0 0}$ & $\mathbf{1 0 0}$ & $\mathbf{1 0 0}$ \\
\hline & Min & $\mathbf{8 4}$ & $\mathbf{3 3}$ & $\mathbf{0}$ \\
\hline
\end{tabular}

Menghitung utility:

Untuk kriteria yang sifatnya "lebih kecil, lebih baik", kriteria ini biasanya dalam bentuk biaya yang harus dikeluarkan (misal kriteria harga, waktu pengiriman barang) menggunakan Persamaan (2)

$$
F x\left(a_{x}\right)=\left(\frac{G_{\max }-G_{\text {out }}}{G_{\max }-G_{\min }}\right) * 100
$$

b. Untuk kriteria yang sifatnya "lebih besar, lebih baik", kriteria ini biasanya dalam bentuk keuntungan. Menggunakan Persamaan (3).

$$
F x\left(a_{x}\right)=\left(\frac{G_{\text {out }-} G_{\min }}{G_{\max -} G_{\min }}\right) * 100
$$

Dimana $F_{X}\left(a_{x}\right)$ merupakan nilai utility kriteria ke $x$ untuk ke x, Gmax merupakan nilai kriteria maksimal, Gmin merupakan nilai kriteria minimal dan Gout merupakan nilai kriteria ke $\mathrm{x}$.

Setelah dilakukan perhitungan keseluruhan nilai utilities setiap kriteria, maka didapatkan hasil seperti yang disajikan pada tabel 9 untuk dosen dan 10 untuk karyawan. 
Tabel 9. Hasil Perhitungan Utility Setiap Kriteria Dosen

\begin{tabular}{ccccccc}
\hline No & $\begin{array}{c}\text { Alternatif } \\
\text { Dosen }\end{array}$ & Q1 & Q2 & Q3 & Q4 & Q5 \\
\hline 1 & AIM (D1) & 1.0 & 1.0 & 0.21 & 0.2 & 0.00 \\
2 & AMU (D2) & 1.0 & 1.0 & 0.00 & 0.0 & 0.23 \\
3 & WHY (D3) & 0.0 & 0.5 & 0.92 & 1.0 & 0.90 \\
4 & DHD (D4) & 1.0 & 1.0 & 1.00 & 0.3 & 0.90 \\
5 & LMP (D5) & 0.0 & 0.0 & 0.71 & 0.0 & 0.21 \\
6 & STA (D6) & 1.0 & 1.0 & 0.96 & 0.2 & 1.00 \\
\hline
\end{tabular}

Tabel 10. Hasil Perhitungan Utility Setiap Kriteria Karyawan

\begin{tabular}{ccccc}
\hline No & $\begin{array}{c}\text { Alternatif } \\
\text { Karyawan }\end{array}$ & Q1 & Q2 & Q3 \\
\hline 1 & ARD (K1) & 1 & 1.0 & 1 \\
2 & HTA (K2) & 0 & 0.5 & 0 \\
3 & JPA (K3) & 1 & 0.0 & 0 \\
\hline
\end{tabular}

\subsubsection{Menghitung Nilai Akhir}

Kemudian dilanjutkan dengan menghitung nilai masing-masing alternatif dengan cara melakukan perkalian nilai utility dengan bobot menggunakan rumus:

$$
N A=\sum_{y=1}^{z} A_{z} F_{x}\left(a_{x}\right)
$$

Dimana NAadalah nilai total alternatif, $\mathrm{A}_{\mathrm{z}}$ adalah hasil normalisasi bobot kriteria dan $\operatorname{Fx}\left(a_{x}\right)$ adalah hasil nilai utlity.

a. Proses perhitungan akhir AIM (D1)

$U_{\mathrm{AIM}(\mathrm{D} 1)}=(1 * 0.2173)+(1 * 0.2065)+(0.21$

$* 0.1956)+(0.2 * 0.1956)+(0 * 0.1847)$

$U_{\mathrm{AIM}(\mathrm{D} 1)}=0.5406$

b. Proses perhitungan akhir AMU (D2)

$U_{\mathrm{AMU}(\mathrm{D} 2)}=(1 * 0.2173)+(1 * 0.2065)+(0 *$

$0.1956)+(0 * 0.1956)+(0.23 * 0.1847)$

$U_{\mathrm{AIM}(\mathrm{D} 1)}=0.4664$

c. Proses perhitungan akhir WHY (D3)

$U_{\mathrm{WHY}(\mathrm{D} 3)}=(0 * 0.2173)+(0.5 * 0.2065)+$ $(0.92 * 0.1956)+(1 * 0.1956)+(0.9 *$ $0.1847)$

$U_{W H Y(D 3)}=0.6450$

d. Proses perhitungan akhir DHD (D4) $U_{\mathrm{DHD}(\mathrm{D} 4)}=(1 * 0.2173)+(1 * 0.2065)+(1 *$ $0.1956)+(0.3 * 0.1956)+(0.9 * 0.1847)$

$U_{D H D(D 4)}=0.8521$

e. Proses perhitungan akhir LMP (D5)

$U_{\text {LMP(D5) }}=(0 * 0.2173)+(0 * 0.2065)+(0.71$

$* 0.1956)+(0 * 0.1956)+(0.21 * 0.1847)$

$U_{L M P(D 5)}=0.1776$

f. Proses perhitungan akhir STA (D6)

$$
\begin{aligned}
& U_{\mathrm{STA}(\mathrm{D} 6)}=(1 * 0.2173)+(1 * 0.2065)+(0.96 \\
& * 0.1956)+(0.2 * 0.1956)+(1 * 0.1847) \\
& U_{\mathrm{STA}(\mathrm{D} 6)}=0.83507
\end{aligned}
$$

Dari hasil perhitungan dosen dan karyawan di atas didapatkan nilai perangkingan dari 6 alternatif dosen dan 3 alternatif karyawan yang memiliki nilai tertinggi hingga yang terendah, yaitu:

Untuk Dosen:
a. Dosen DHD dengan total nilai $=0.8521$
b. Dosen STA dengan total nilai $=0.8350$
c. Dosen WHY dengan total nilai $=0.6450$
d. Dosen AIM dengan total nilai $=0.5406$
e. Dosen AMU dengan total nilai $=0.4664$
f. Dosen LMP dengan total nilai $=0.1776$

Untuk Karyawan:

a. Karyawan ARD dengan total nilai $=0.9998$

b. Karyawan JPA dengan total nilai $=0.3571$

c. Karyawan HTA dengan total nilai $=0.1721$

Sehingga dari hasil perhitungan didapatkan hasil penilaian seperti pada tabel 11 dan tabel 12 berikut:

Tabel 11. Hasil Penilaian Dosen

\begin{tabular}{clcc}
\hline No & Nama Dosen & $\begin{array}{c}\text { Hasil } \\
\text { Penilaian }\end{array}$ & Peringkat \\
\hline 1 & Dosen AIM & 0.5406 & 4 \\
2 & Dosen AMU & 0.4664 & 5 \\
3 & Dosen WHY & 0.6450 & 3 \\
4 & Dosen DHD & 0.8521 & 1 \\
5 & Dosen LMP & 0.1776 & 6 \\
6 & Dosen STA & 0.8350 & 2 \\
\hline
\end{tabular}

Tabel 12. Hasil Penilaian Karyawan

\begin{tabular}{clcc}
\hline No & Nama Karyawan & $\begin{array}{c}\text { Hasil } \\
\text { Penilaian }\end{array}$ & Peringkat \\
\hline 1 & Karyawan ARD & 0.5406 & 1 \\
2 & Karyawan HTA & 0.1721 & 3 \\
3 & Karyawan JPA & 0.3571 & 2 \\
\hline
\end{tabular}

\section{Kesimpulan}

Dari rangkaian proses perhitungan data denganmenggunakan metode SMART sesuai dengan langkah dan kriteria yang telah ditetapkan menghasilkan dari 6 data staf dosen dan 3 karyawan STMIK Indonesia yang diambil secara acak, untuk dosen berprestasi peringkat pertama dengan Dosen DHD jumlah nilai 0.8521 peringkat kedua Dosen STA dengan nilai 0.8350 dan peringkat tiga Dosen WHY dengan nilai 0.6450 sedangkan untuk karyawan berprestasi peringkat pertaman Karyawan ARD jumlah nilai 0.5406, peringkat dua Karyawan JPA dengan nilai 0.3571 dan peringkat ketiga Karyawan HTA dengan nilai 0.1721 .

\section{Daftar Rujukan}

[1] Agustina, M. (2019). Penentuan Team Leader, Supervisor dan Facility Services pada Perusahaan Jasa Berdasarkan Metode Simple Multi Attribute Rating Technique (SMART). Jurnal Ilmiah Matrik, 21(1), 64-75. DOI: https://doi.org/10.33557/jurnalmatrik.v21i1.519. 
[2] Setiawan, W., Pranoto, N., \& Huda, K. (2020). Employee [9] Andani, S. R. (2019). Penerapan Metode SMART dalam Performance Evaluation Decision Support System with the SMART (Simple Multi-Attribute Rating Technique) Method. Jurnal RESTI (Rekayasa Sistem dan Teknologi Informasi), 4(1), 50 - 55. DOI: https://doi.org/10.29207/resti.v4i1.1384 .

[3] Irviani, R., Dinulhaq, I., Irawan, D., Renaldo, R., Kasmi., \& Maseleno, A. (2018). Areas Prone of the Bad Nutrition based Multi Attribute Decision Making with Fuzzy Simple Additive Weighting for Optimal Analysis. International Journal of Pure and Applied Mathematics. 118(7). 589-596

[4] Susanto, A., Latifah, L., Nuryasin, \& Fitriyani, A. (2017). Decision Support Systems Design On Sharia Financing Using Yager's Fuzzy Decision Model. International Conference on Cyber and IT Service Management (CITSM). DOI: https://doi.org/10.1109/citsm.2017.8089263 .

[5] Ukkas, M. I., Pratiwi, H., \& Purnamasari, D. (2016). Sistem Pendukung Keputusan Penentuan Supplier Bahan Bangunan Menggunakan Metode Smart (Simple Multi Attribute Rating Technique) Pada Toko Bintang Keramik Jaya. Sebatik, 16(1), 3443. DOI: https://doi.org/10.46984/sebatik.v16i1.73 .

[6] Sembiring, B. S. B., Zarlis, M., Sawalluddin., Agusnady, A., \& Qowidho, T. (2019). Comparison of SMART and SAW Methods in Decision Making. Journal of Physics: Conference Series, 1255. DOI: http://doi.org/10.1088/1742-6596/1255/1/012095 .

[7] Berutu, S., Na'am, J., \& -, S. (2019). Sistem Pendukung Keputusan Penilaian Kinerja Pegawai Untuk Kenaikan Jabatan Menggunakan Metode Simple Multi Attribute Retting Tech (SMART). Jurnal Ekobistek, 8(1).

[8] Taylor, J. M., \& Love, B. N. (2014). Simple Multi-Attribute Rating Technique For Renewable Energy Deployment Decisions (SMART REDD). The Journal of Defense Modeling and Simulation: Applications, Methodology, Technology, 11(3), 227232. DOI: https://doi.org/10.1177/1548512914525516 . Pengambilan Keputusan Penerima Beasiswa Yayasan AMIK Tunas Bangsa. Jurnal Sistem dan Teknologi Informasi (JUSTIN), 7(3). DOI: http://dx.doi.org/10.26418/justin.v7i3.30112 .

[10] Agustina, M. (2019). Penentuan Team Leader, Supervisor dan Facility Services pada Perusahaan Jasa Berdasarkan Metode Simple Multi Attribute Rating Technique (SMART). Jurnal Ilmiah Matrik, 21(1), 64-75. DOI: https://doi.org/10.33557/jurnalmatrik.v21i1.519 .

[11] Warnilah, A. I., Hawa, I. N., \& Mulyani, Y. S. (2020). The Analysis of Determining Credit Worthiness Using Weighted Product and SMART Methods In SPB Cooperatives. Indonesian Journal of Information Systems, 2(2), 61. DOI: https://doi.org/10.24002/ijis.v2i2.3121 .

[12] Jahir, A., Setiawan, I., \& Arta, A. D. (2019). Decision Support System to Determine the Achievement of Students Using Simple Multi-Attribute Rating Technique (SMART). IJIIS: International Journal of Informatics and Information Systems, 2(2), 39-47. DOI: https://doi.org/10.47738/ijiis.v2i2.12

[13]Borissova, D., \& Keremedchiev, D. (2019). Group Decision Making in Evaluation and Ranking of Students by Extended Simple Multi-Attribute Rating Technique. Cybernetics and Information Technologies, 19(3), 45-56. DOI: https://doi.org/10.2478/cait-2019-0025 .

[14]Rasheed, R., Javed, H., Rizwan, A., Yasar, A., Tabinda, A. B., Mahfooz, Y., Wang, Y., \& Su, Y. (2020). Sustainability and CDM Potential Analysis of A Novel Vs Conventional Bioenergy Projects In South Asia By Multi-Criteria Decision-Making Method Environmental Science and Pollution Research, 27(18), 23081-23093. DOI: https://doi.org/10.1007/s11356-020-08862-6

[15]Lavik, M. S., Hardaker, J. B., Lien, G., \& Berge, T. W. (2020). A Multi-Attribute Decision Analysis of Pest Management Strategies For Norwegian Crop Farmers. Agricultural Systems, 178. DOI: https://doi.org/10.1016/j.agsy.2019.102741 